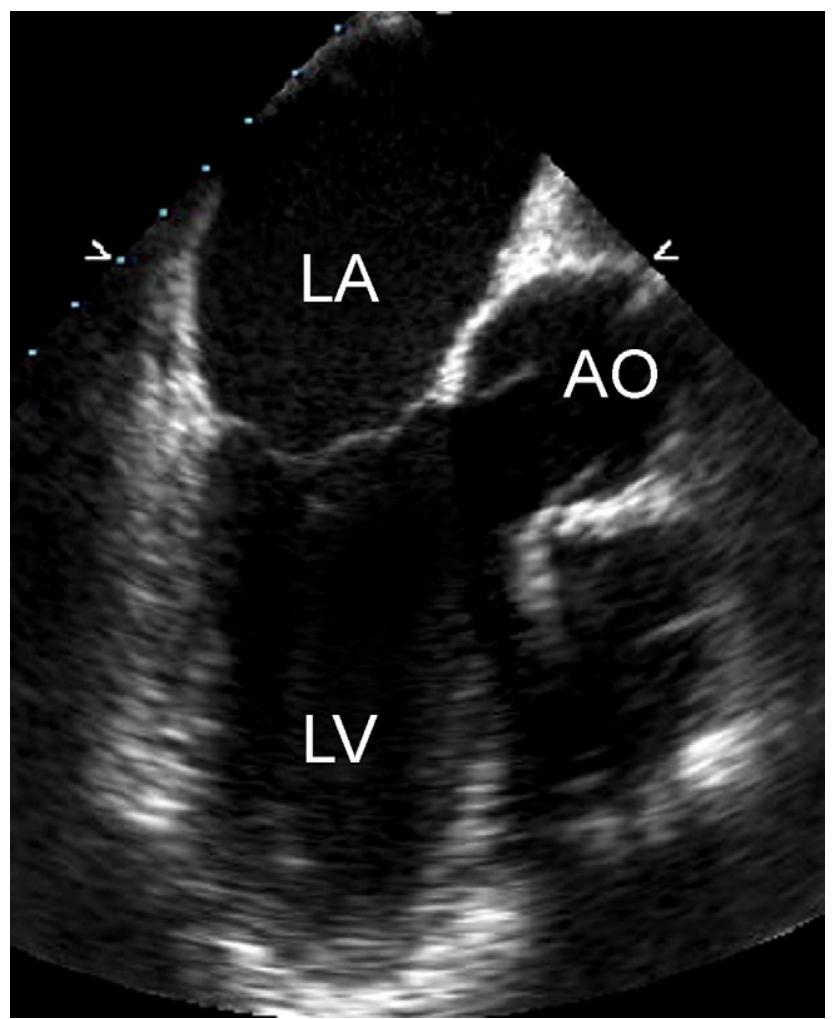

FIGURE 2. Midesophageal 2-chamber long-axis view of the aortic root. The prosthetic aortic root replacement is evident, with normal full systolic excursion of the reimplanted native aortic cusps (David V). $L A$, Left atrium; $L V$, left ventricle; $A O$, aortic root.

The minimum aortic procedure required was aortic root replacement. The sparing of the native aortic valve had the added advantages of excellent hemodynamics and no requirement for anticoagulation. Because the ascending aorta and aortic arch were of upper normal caliber, surgical replacement was not absolutely required at the same time.

Our rationale for concomitant replacement was 2-fold. First, it added negligible extra perioperative risk, given his young age and our extensive experience in aortic arch surgery. ${ }^{5} \mathrm{Sec}-$ ond, the patient was at a much higher risk of type A dissection in the near future, given the natural history of LDS. ${ }^{1-4}$

In summary, the clinical observation from this case is that surgical management of the proximal thoracic aorta in patients with LDS should take into account not only the presenting aortic pathology but also the likely future aortic syndromes based on the natural history of this aggressive vasculopathy. The aortopathy seen in patients with LDS merits an aggressive surgical approach, given its life-threatening presentations.

\section{References}

1. Loeys BL, Chen J, Neptune ER, Judge DP, Podowski M, Holm T, et al. A syndrome of altered cardiovascular, craniofacial, neurocognitive, and skeletal development caused by mutations in TGFBR1 or TGFBR2. Nat Gen. 2005;37:275-81.

2. Lee RS, Fazel S, Schwarze U, Fleischmann D, Berry GJ, Liang D, et al. Rapid aneurismal degeneration of a Stanford type B aortic dissection in a patient with Loeys-Dietz syndrome. J Thorac Cardiovasc Surg. 2007;134:242-3.

3. Melenovsky V, Adamira M, Kautznerova D, Voska L, Weichet J, Loeys B, et al. Aortic dissection in a young man with Loeys-Dietz syndrome. J Thorac Cardiovasc Surg. 2008; 135:1174-5.

4. Williams JA, Loeys BL, Nwakanma LU, Dietz HC, Spevak PJ, Patel ND, et al Early surgical experience with Loeys-Dietz: a new syndrome of aggressive thoracic aortic aneurysm disease. Ann Thorac Surg. 2007;83(suppl):S757-63.

5. Appoo JJ, Augoustides JG, Pochettino A, Savino JS, McGarvey ML, Cowie DC, et al. Perioperative outcome in adults undergoing elective deep hypothermic circulatory arrest with retrograde cerebral perfusion in proximal aortic arch repair: evaluation of protocol-based care. J Cardiothorac Vasc Anesth. 2006;20:3-7.

\title{
A simple modification of inflow cannula to reduce recirculation of venovenous extracorporeal membrane oxygenation
}

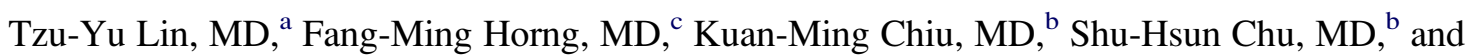 \\ Jiann-Shing Shieh, PhD, ${ }^{\mathrm{d}}$ Taipei and Tao-Yuan County, Taiwan
}

\footnotetext{
From the Department of Anesthesia, ${ }^{\mathrm{a}}$ Division of Cardiovascular Surgery, ${ }^{\mathrm{b}}$ and Division of Critical Care, ${ }^{\mathrm{c}}$ Far-Eastern Memorial Hospital, Taipei, Taiwan; and the Department of Mechanical Engineering, Yuan-Ze University, ${ }^{\mathrm{d}}$ Tao-Yuan County, Taiwan.

Received for publication Jan 28, 2008; accepted for publication Feb 27, 2008; available ahead of print Sept 1, 2008

Address for reprints: Fang-Ming Horng, MD, Division of Critical Care, Far-Eastern

Memorial Hospital, 13F, 21, Sec 2, Nan-Ya S Rd, Ban-Ciao, Taipei County, 220,

Taiwan (E-mail: philip@mail.femh.org.tw).

J Thorac Cardiovasc Surg 2009;138:503-6

$0022-5223 / \$ 36.00$

Copyright (C) 2009 by The American Association for Thoracic Surgery

doi:10.1016/j.jtcvs.2008.02.095
}

Venovenous extracorporeal membrane oxygenation (VVECMO) is commonly used in respiratory distress syndrome. Double cannulation of jugular and femoral veins is the most practical clinical setting for adult patients. Despite the excellent efficiency of membranous oxygenator, recirculation impairs oxygen delivery. There are several clinically practical methods to quantify and monitor recirculation in VV-ECMO applications. However, limited interventions could be done to reduce recirculation. Theoretically, an attempt to insert the inflow cannula into the 
right ventricle and even the main pulmonary artery may avoid mixing and increase systemic saturation. The procedural complexity and potential risks remain the drawbacks. We introduce a simple modification of manipulating the direction of inflow cannula to address the issue. The preferential flow toward the tricuspid valve and right ventricle significantly increases the efficiency of oxygen delivery. Our findings indicate that the redesign of the conventional cannula results in a significant reduction of recirculation, thereby demonstrating a significant improvement in oxygenation while on VV-ECMO. Patients with extremely poor oxygenation caused by pulmonary disorders are indicated for VV-ECMO.

VV-ECMO is usually considered as the last resort after mechanical ventilation and inhaled nitric oxide for extremely poor oxygenation with various causes. However, based on its intrinsic setting, recirculation between outflow and inflow cannulae remains a clinical obstacle. Recirculation per se significantly impairs systemic oxygenation and contradicts the primary purpose of this practice. Various modifications have been proposed to solve this problem. Locating the outflow cannula in the most desaturated blood and the inflow cannula away from the outflow cannula or toward the downstream chambers (right ventricle or pulmonary artery) is thought to be useful. Most VV-ECMO procedures are performed at bedside. Both inflow and outflow cannulae are inserted by using Seldinger's techniques. Regardless of how we increase the size of cannulae, ECMO flow, or meticulous adjustment of the depth of insertion, recirculation is not always avoidable.

We introduce a simple modification of the commercially available cannula to redirect inflow and to reduce recirculation. This modification provides a clinically practical method to improve oxygen delivery.

\section{CLINICAL SUMMARY}

Fever and shortness of breath progressively developed in a 25-year-old man in a 1-week period. He was a smoker and had no recent travel or contact history. He had a productive cough with blood-tinged sputum, high fever with chills, and aggravated dyspnea, and was brought to the emergency department. The blood gas analysis revealed poor arterial oxygen saturation $\left(\mathrm{SAO}_{2} 72 \%\right)$. Chest radiography showed diffuse pulmonary infiltrates, and viral pneumonitis was observed. Because of the clinical deterioration of the patient's condition, he was intubated for mechanical ventilation. Azotemia, anuria, and pulmonary hemorrhage via endotracheal tube were noted. The fraction of inspired oxygen $\left(\mathrm{FIO}_{2}\right)$ was increased to $100 \%$, followed by inhaled nitric oxide. Persistent hypoxemia remained unchanged. The ratio of arterial oxygen tension over $\mathrm{FiO}_{2}$ was 56. Extracorporeal oxygenation was requested. Because of adequate cardiac performance and isolated pulmonary dysfunction, VVECMO was set up. Mixed venous blood was drawn via

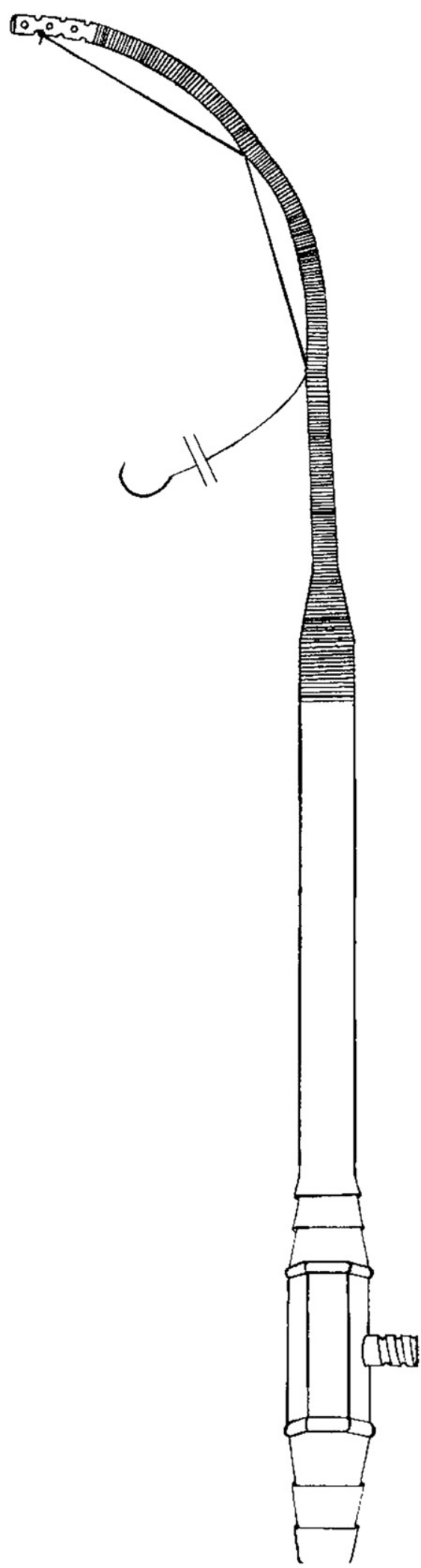

FIGURE 1. 3-0 Prolene was used to make 3 consecutive bites over the proximal third of the 21F Medtronic (Minneapolis, Minn) femoral artery cannula. The desired curvature was made by pulling up the suture. 
TABLE 1. Efficacy of oxygen delivery of venovenous extracorporeal membrane oxygenation using conventional versus modified cannula

\begin{tabular}{|c|c|c|c|c|c|c|c|}
\hline & \multicolumn{2}{|c|}{$\mathrm{P}_{\mathrm{AO}_{2}}(\mathrm{~mm} \mathrm{Hg})$} & \multicolumn{2}{|c|}{$\mathrm{PaCO}_{2}(\mathrm{~mm} \mathrm{Hg})$} & \multirow[b]{2}{*}{$\mathrm{S}_{\mathrm{AO}_{2}}$} & \multirow{2}{*}{$\begin{array}{c}\mathbf{H b} \\
(\mathrm{g} / \mathrm{dL})\end{array}$} & \multirow{2}{*}{$\begin{array}{r}\text { Pump } \\
\text { flow }\end{array}$} \\
\hline & $\mathbf{R A}$ & ECMO & RA & ECMO & & & \\
\hline $\begin{array}{l}\text { Conventional } \\
\text { cannula }\end{array}$ & 54 & 427 & 43 & 16 & $87 \%$ & 14.3 & $\begin{array}{c}4.6 \\
\mathrm{~L} / \mathrm{min}\end{array}$ \\
\hline $\begin{array}{l}\text { Modified } \\
\text { cannula }\end{array}$ & 83 & 395 & 41 & 17 & $96 \%$ & 13.9 & $\begin{array}{c}4.6 \\
\mathrm{~L} / \mathrm{min}\end{array}$ \\
\hline
\end{tabular}

$R A$, Radial artery; $E C M O$, extracorporeal membrane oxygenation; $\mathrm{SAO}_{2}$, right thumb transcutaneous oxygen saturation; $H b$, hemoglobin. ECMO oxygenator setting: $\mathrm{FIO}_{2}: 100 \%$, gas flow: $2 \mathrm{~L} / \mathrm{min}$.

the right femoral vein, and oxygenated blood was returned via the right jugular vein. $\mathrm{SAO}_{2}$ increased to $87 \%$ under the ECMO flow of $4.6 \mathrm{~L} / \mathrm{min}$ and $100 \% \mathrm{FIO}_{2}$. Attempts to adjust the position of cannulae did not improve the systemic saturation. On the following day, a modification of inflow cannula was made. A 3-0 Prolene was used to bend the 21F Medtronic (Minneapolis, Minn) femoral artery cannula toward the right ventricle (Figure 1). The Prolene suture was knotted over the tip and stopped by 2 turning points to create the curvature. Pulling up the 3-0 Prolene made the tip of cannula adjustable. The inflow cannula was changed by this adjustable cannula. The suture was pulled and fixed on the female luer lock of the cannula. Under the same ECMO flow, the systemic oxygenation reached $96 \%$ after this modification (Table 1). The chest films showed a lazy curvature of the radio-opaque portion of the inflow cannula (Figure 2). The soft plastic portion of the inflow cannula was identified by transesophageal echocardiography (Figure 3). The jet of ECMO inflow, which was observed on the transthoracic or transesophageal echocardiography, was toward the right ventricle.

The patient was weaned from VV-ECMO 10 days later. The patient was extubated 2 more days later and had a smooth recovery thereafter.

\section{DISCUSSION}

Various methods exist for the clinical practice of VVECMO. Among the clinical techniques used are the singlelumen catheter for tidal flow VV-ECMO, dual-lumen catheter, and double and even triple cannulation ${ }^{1}$ of the jugular and femoral veins. Double cannulation is the most commonly used practice. It has been well demonstrated that femoroatrial bypass provides higher maximal flow and higher pulmonary arterial oxygen saturation, and requires comparatively less flow to maintain an equivalent oxygen saturation than atriofemoral bypass. ${ }^{2}$

Because recirculation during VV-ECMO reduces oxygen delivery to the patient, efforts to reduce recirculation could optimize patient care, but the cannulae designed for percutaneous insertion limit malleability. Clinically adjustable parameters are the fraction of inspired oxygen, gas flow, ECMO flow, and depth of cannulae. However, recirculation

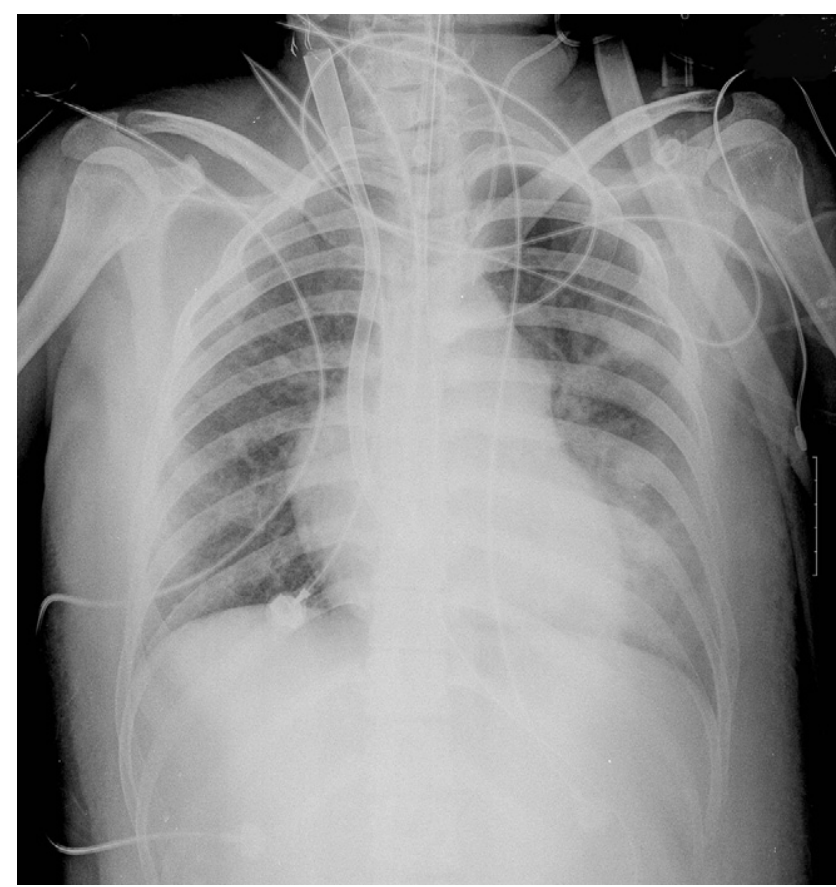

FIGURE 2. Plain chest radiograph shows the lazy curvature of the inflow cannula from the right neck base toward the right ventricle. The drawing cannula was located below the diaphragm.

is still unavoidable. Quantification of recirculation by conventional blood gas analyses, thermodilution, or dilutional ultrasound monitoring ${ }^{3}$ during VV-ECMO has been reported. All of these methods have been used to measure changes in baseline recirculation in the face of cannula repositioning and drug-induced cardiac output changes. Ideally, the ECMO flow necessary to maintain patients' oxygen saturation greater than $90 \%$ should be significantly lower than the cardiac output. The venous oxygen tension derived from the outflow cannula is within physiologic range, and less

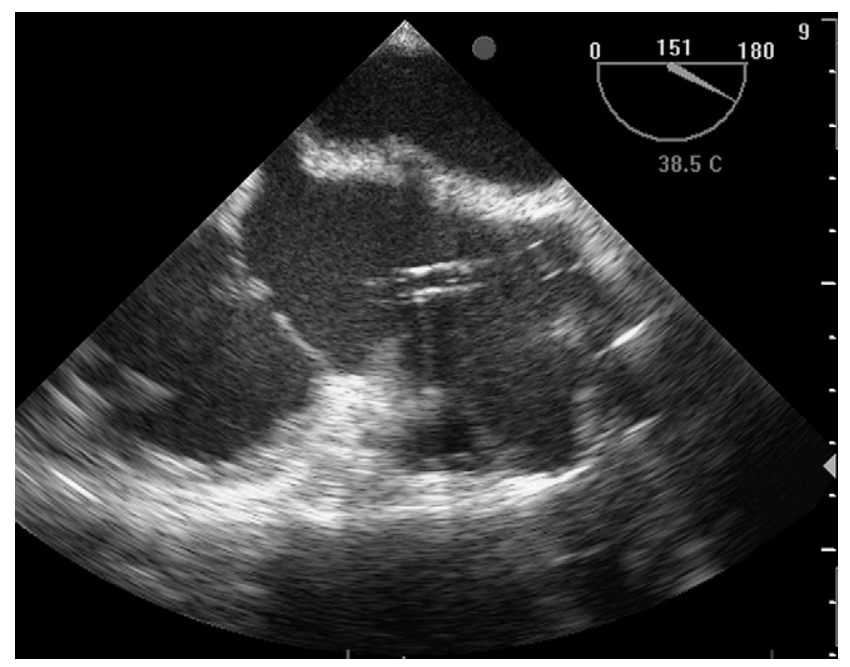

FIGURE 3. Transesophageal echocardiography reveals the tip of the inflow cannula aiming at the tricuspid valve. 
than $10 \%$ of arterial oxygen tension is derived from the inflow cannula. This evidence rules out clinically relevant recirculation volume. ${ }^{4}$ However, limited effective interventions could improve oxygen delivery. Relocating the inflow cannula to the main pulmonary artery by a surgical approach was reported by our team. ${ }^{5}$ Surgical invasiveness remains a concern. Therefore, we developed this minimally invasive approach to manipulate the inflow cannula to redirect the flow and avoid mixing.

The inflow jet toward the right ventricle limits the recirculation by diversion of flow direction and reduction of mixing oxygenated and deoxygenated blood inside the right atrium or vena cavae. The depth of insertion should be estimated in advance. Plain chest radiography should offer sufficient information on the length and desired curvature. Current digital films allow us to measure the exact distance between 2 points on the screen. The curvature was only apparent inside the right atrium. The portion of cannula inside the innominate vein and superior vena cava did not allow for bending. Therefore, the turning points for the suture to stop are mainly located over the proximal third of the inserted length. The monofilament stitch was favorable for this application because of less possibility of infection. However, braided sutures such as Ethibond Excel (Ethicon, Somerville, NJ) have better strength. Once the cannula was inserted, the proper location was evaluated by arterial blood gas, chest films, and transthoracic or transesophageal echocardiography. By turning the cannula and pulling the thread to bend the tip toward the tricuspid valve, minimal recirculation was achieved. By sampling the oxygen saturation of both inflow and outflow cannulae, the proper location was determined without difficulty.

Some might be concerned about the risk of arrhythmia. Care should be given to avoid the jet irritation of the right ventricle. If arrhythmia occurs, readjustment under echocardiographic guidance should be done. The practice of manipulating the endovascular devices is common with interventionists and cardiovascular surgeons.

\section{CONCLUSIONS}

We have introduced a simple bedside maneuver of manipulating the inflow cannula of VV-ECMO to significantly reduce recirculation and increase systemic oxygen saturation. Percutaneous, tailor-made, malleable cannula may be available in the near future. Then, the troublesome issue could be reduced to the minimal extent.

\section{References}

1. Ichiba S, Peek GJ, Sosnowski AW, Brennan KJ, Firmin RK. Modifying a venovenous extracorporeal membrane oxygenation circuit to reduce recirculation. Ann Thorac Surg. 2000;69:298-9.

2. Rich PB, Awad SS, Crotti S, Hirschl RB, Bartlett RH, Schreiner RJ. A prospective comparison of atrio-femoral and femoro-atrial flow in adult venovenous extracorporeal life support. J Thorac Cardiovasc Surg. 1998;116:628-32.

3. Darling EM, Crowell T, Searles BE. Use of dilutional ultrasound monitoring to detect changes in recirculation during venovenous extracorporeal membrane oxygenation in swine. ASAIO J. 2006;52:522-4.

4. Locker GJ, Losert H, Schellongowski P, Thalhammer F, Knapp S, et al. Bedside exclusion of clinically significant recirculation volume during venovenous ECMO using conventional blood gas analyses. J Clin Anesth. 2003;15:441-5.

5. Chiu KM, Li SJ, Hung FM, Chu SH, Lin TY. Right heart bypass for acute traumatic respiratory distress syndrome. ASAIO J. 2005;51:826-8.

\title{
A workbench to make artificial chordal loops for mitral valve repair
}

\author{
Toshihiko Shibata, MD, ${ }^{a}$ Kazushige Inoue, MD, ${ }^{\mathrm{b}}$ Takeshi Ikuta, MD, ${ }^{\mathrm{b}}$ and Yasuyuki Bito, MD, \\ Osaka and Amagasaki, Japan
}

Mitral valve repair using an expanded polytetrafluoroethylene (ePTFE; Gore-Tex, W.L. Gore and Associates, Flagstaff, AZ) chorda is a reliable method. To determine the appropriate length of artificial chorda, some experiment-

\footnotetext{
From the Division of Cardiovascular Surgery, ${ }^{\mathrm{a}}$ Osaka City General Hospital, Osaka, Japan, and the Division of Cardiovascular Surgery, ${ }^{\mathrm{b}}$ Kansai Rosai Hospital, Amagasaki, Japan.

Received for publication Jan 3, 2008; accepted for publication Jan 12, 2008; available ahead of print Sept 1, 2008.

Address for reprints: Toshihiko Shibata, MD, The Division of Cardiovascular Surgery, Osaka City General Hospital, 2-1-13, Miyakojima-hondori, Miyakojima, Osaka, 534-0021, Japan (E-mail: shibata@msic.med.osaka-cu.ac.jp).

J Thorac Cardiovasc Surg 2009;138:506-7

$0022-5223 / \$ 36.00$

Copyright (c) 2009 by The American Association for Thoracic Surgery doi:10.1016/j.jtcvs.2008.01.048
}

ing is required; thus many methods to determine the right length have been advocated. Von Oppell and Mohr demonstrated a technique using a ruler to make ePTFE loops of premeasured length. ${ }^{1}$ Here, we describe a novel loop maker for artificial chordal reconstruction.

\section{TECHNIQUE}

We developed a workbench to make artificial chordal loop for mitral valve repair (03-5425; Geister, Tuttlingen, Germany). This device consists of a metal plate with 6 small, diagonally positioned rods and 2 pledget holders (Figure 1 ). The distances between the pledget holder on the reference line and the rods ranges from 15 to $25 \mathrm{~mm}$, notched at 2-mm intervals, and from 16 to $26 \mathrm{~mm}$ when used upside 